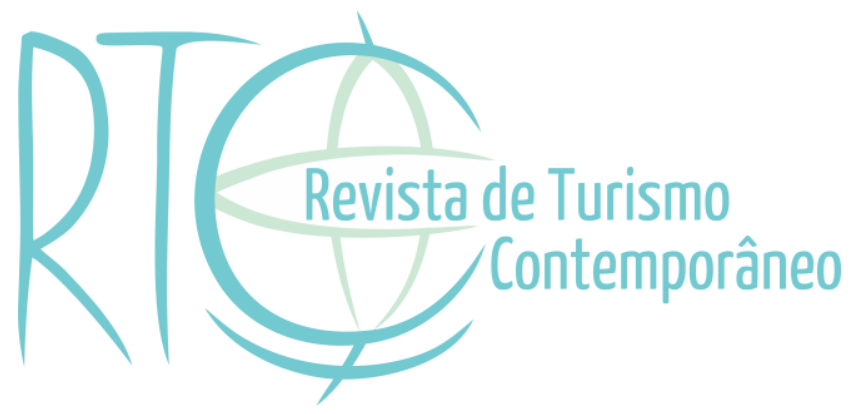

\title{
Economia formal e desenvolvimento econômico turístico do Circuito dos Diamantes - MG
}

Formal economy and tourist economic development of Circuito dos Diamantes - MG

Erick de Oliveira Faria

Mestrando em Geografia pela Pontifícia Universidade Católica de Minas Gerais - PUCMG, Belo Horizonte/MG, Brasil

E-mail: erickolifaria@gmail.com

\section{Manuella Biagioni Barbosa Teixeira}

Bacharel em Turismo pela Universidade Federal de Minas Gerais (UFMG), Belo Horizonte/MG, Brasil

E-mail: manuellabiagioni@gmail.com 


\section{RESUMO}

Os circuitos turísticos de Minas Gerais foram criados pela Secretaria de Turismo do Estado, visando o fortalecimento do turismo a partir da organização entre municípios com potencial turístico, levando em consideração os aspectos econômicos, sociais e culturais comuns da região. O presente estudo buscou analisar o Circuito dos Diamantes, o mais antigo dos circuitos turísticos de Minas Gerais, por meio da sua economia formal a partir da evolução do número de estabelecimentos no setor e de seu mercado de trabalho formal, dentre as atividades econômicas do turismo propostas pela Organização Mundial de Turismo (OMT) entre os períodos de 2006 e 2014 utilizando-se da base de dados da Relações Anuais de Informações Sociais (RAIS). De forma complementar analisou-se o impacto dos incentivos financeiros por parte do Estado de Minas Gerais por meio do ICMS turístico como uma forma de verificar a eficácia e a contribuição que estes recursos têm para impulsionar o turismo. Os resultados apontam que apesar dos incentivos econômicos o mercado formal do turismo ainda é pequeno, com pouco crescimento no período analisado, o que coloca em questão a eficácia das políticas públicas no setor.

Palavras-chave: Desenvolvimento Econômico Turístico. Circuito dos Diamantes. Economia Formal.

\section{ABSTRACT}

The tourist circuits of Minas Gerais were created by the State Tourism Secretary, aiming at strengthening tourism by organizing among municipalities with tourist potential, taking into account the common economic, social and cultural aspects of the region. The present study sought to analyze the Diamond Circuit, the oldest of the tourist circuits of Minas Gerais, through its formal economy based on the evolution of the number of establishments in the sector and its formal labor market, among the economic activities of the proposed tourism By the World Tourism Organization (UNWTO) between 2006 and 2014 through the Annual Social Relations Information Database (RAIS). In a complementary way, the impact of the financial incentives by the State of Minas Gerais through tourism ICMS was analyzed as a way to verify the effectiveness and the contribution that these resources have to boost tourism. The results indicate that despite the economic incentives, the formal tourism market is still small, with little growth in the analyzed period, which calls into question the effectiveness of public policies in the sector.

Keywords: Tourism Circuits. Circuit of Diamonds. Labor Market in Tourism. 


\section{INTRODUÇÃO}

O turismo é uma atividade que, do ponto de vista econômico é, representada pelo conjunto de ações de compra e venda de serviços nos setores de alimentação, recreação, lazer e demais características referentes a área. É uma economia gerada através do deslocamento do turista, de sua residência, até o local onde vai exercer as atividades do turismo (Veloso, 2003).

Visando o desenvolvimento do turismo no Brasil, foi criado em 2003 o Ministério do Turismo (MTur), cujo foco maior consiste na regionalidade do turismo. Juntamente com a criação de um Ministério dedicado exclusivamente ao Turismo, houve uma reestruturação na Política Nacional de Turismo (PNT), na qual se buscou um modelo capaz de contemplar o desenvolvimento social, econômico e cultural do turismo no Brasil (Solha, 2005).

A partir da Lei n 13.341 (1999), o Estado de Minas Gerais criou a Secretaria Estadual de Turismo (SETUR), baseando-se nos conceitos de descentralização e regionalização do turismo. Uma metodologia de indução e estímulo foi criada a fim de estimular e integrar cidades potenciais para a formação dos Circuitos Turísticos de Minas Gerais. O Estado de Minas Gerais, em conformidade com as propostas do PNT, vem buscando desde então, estruturar Circuitos Turísticos, com o propósito de atrair maior fluxo turístico para regiões com potencial para desenvolvimento do turismo. (Emmendoerfer, Silva, \& Lima, 2011).

Os Circuitos Turísticos são regiões que, por meio da interação dos municípios participantes, desenvolvem planos para o desenvolvimento do turismo regional. Os circuitos turísticos para Brandão (2001) são caracterizados pela história, cultura e natureza, elementos fundamentais e atrativos na atração de turistas para a região.

Os Circuitos Turísticos abrigam um conjunto de municípios de uma mesma região, com afinidades culturais, sociais e econômicas que se unem para organizar e desenvolver a atividade turística regional de forma sustentável, consolidando uma identidade regional. O trabalho destas entidades se dá por meio da integração contínua dos municípios, gestores públicos, iniciativa privada e sociedade civil, consolidando uma identidade regional e protagonizando o desenvolvimento por meio de alianças e parcerias (Setur, 2003).

Um dos primeiros Circuitos Turísticos certificados em Minas Gerais é o Circuito dos Diamantes, localizado na mesorregião do Jequitinhonha, no Estado de Minas Gerais, formado por 14 municípios, por meio de um convênio celebrado em 1977, entre a Empresa Brasileira de Turismo (EMBRATUR) e a Secretaria de Planejamento da Presidência da República. Entre as cidades que compõem o circuito, estão Serro e Diamantina, que no século XVIII e XIX assumiram o papel protagonista no cenário colonial de Minas Gerias, uma como protagonista 
na extração mineral, e a outra como cidade diretamente envolvida na Inconfidência Mineira, respectivamente.

O desenvolvimento econômico do turismo é um estudo complexo que se deve levar em consideração os recursos movimentados nos setores públicos e privados das atividades presentes no setor. Segundo Fuchs (2013) a participação de um município em um circuito turístico, ou região de desenvolvimento de turismo, não necessariamente o faz efetivar políticas públicas de desenvolvimento do setor. A dificuldade em se conseguir dados secundários referente ao desenvolvimento econômico do turismo ainda é um desafio aos pesquisadores que desejam investigar esta área. Uma das maneiras de se verificar o crescimento das atividades turísticas é por meio da análise dos estabelecimentos e do mercado de trabalho formal em setores estratégicos nos circuitos turísticos. Esta metodologia foi utilizada por Árias e Barbosa (2007), que analisaram o mercado de trabalho formal do turismo por meio dos perfis de emprego e remuneração dos profissionais, permitindo assim traçar um panorama do estoque de empregos ao longo de uma série temporal.

Apesar do turismo ser composto por atividades no ramo formal e informal da economia, uma análise do crescimento de atividades formais nos permite analisar o panorama de crescimento ou não das atividades turísticas em uma dada região, neste caso, circuito turístico. O presente estudo analisou a evolução do mercado de trabalho e o número de estabelecimentos em atividades definidas pelo Organização Mundial do Turismo (OMT) como atividades relacionadas ao turismo. Em complemento a esta análise, buscou-se fazer um panorama dos incentivos recebidos a partir do repasse do Imposto Sobre Circulação de Mercadorias e Serviços (ICMS) estadual aos municípios, como um incentivo ao desenvolvimento do turismo.

\subsection{Circuito dos Diamantes}

As cidades do Circuito dos Diamantes têm em comum suas origens no século XVII ligadas a exploração do ouro e diamante, nas cidades que compõem o circuito, o que culminou no desenvolvimento e crescimento das cidades da região. Segundo Mendonça et al. (2005), no final do século XX houve uma tentativa de dinamizar a economia na região, implantando pequenas indústrias, principalmente do setor têxtil. A industrialização na região apresentou índices de crescimento no início de sua implantação, porém, com a concorrência de outras cidades da região, e seguindo uma tendência de desindustrialização no Brasil, a 
região de Diamantina viu seus índices de industrialização serem reduzidos no fim do século $\mathrm{XX}$.

Como alternativa ao processo de industrialização que não se consolidou, a cidade de Diamantina encontrou no turismo um potencial de atração e fixação de investimentos no município. Em 1999 a efetivação da cidade como Patrimônio Histórico da Humanidade concedido pela Organização das Nações Unidas para a Educação, a Ciência e a Cultura (UNESCO), foi o marco inicial para consolidação do turismo no município e na região (Mendonça et al., 2005). A SETUR, com sua política de crescimento regional do turismo, identificou uma oportunidade para a criação do Circuito dos Diamantes, visando desenvolver e consolidar o turismo nas cidades próximas a Diamantina.

O Circuito dos Diamantes conta com diversas atrações turísticas, que vão das visitas aos muitos locais históricos, até às atividades relacionadas ao ecoturismo na Serra do Espinhaço. O circuito é conhecido não apenas pelo turismo de lazer, mas também pelo turismo de eventos, como o carnaval, o turismo gastronômico, famosa atração na cidade do Serro e seus produtores de queijo e também o turismo cultural, nos diversos museus das cidades do circuito. 


\section{Figura 1 - Municípios que compõem o Circuito dos Diamantes - Minas Gerais}

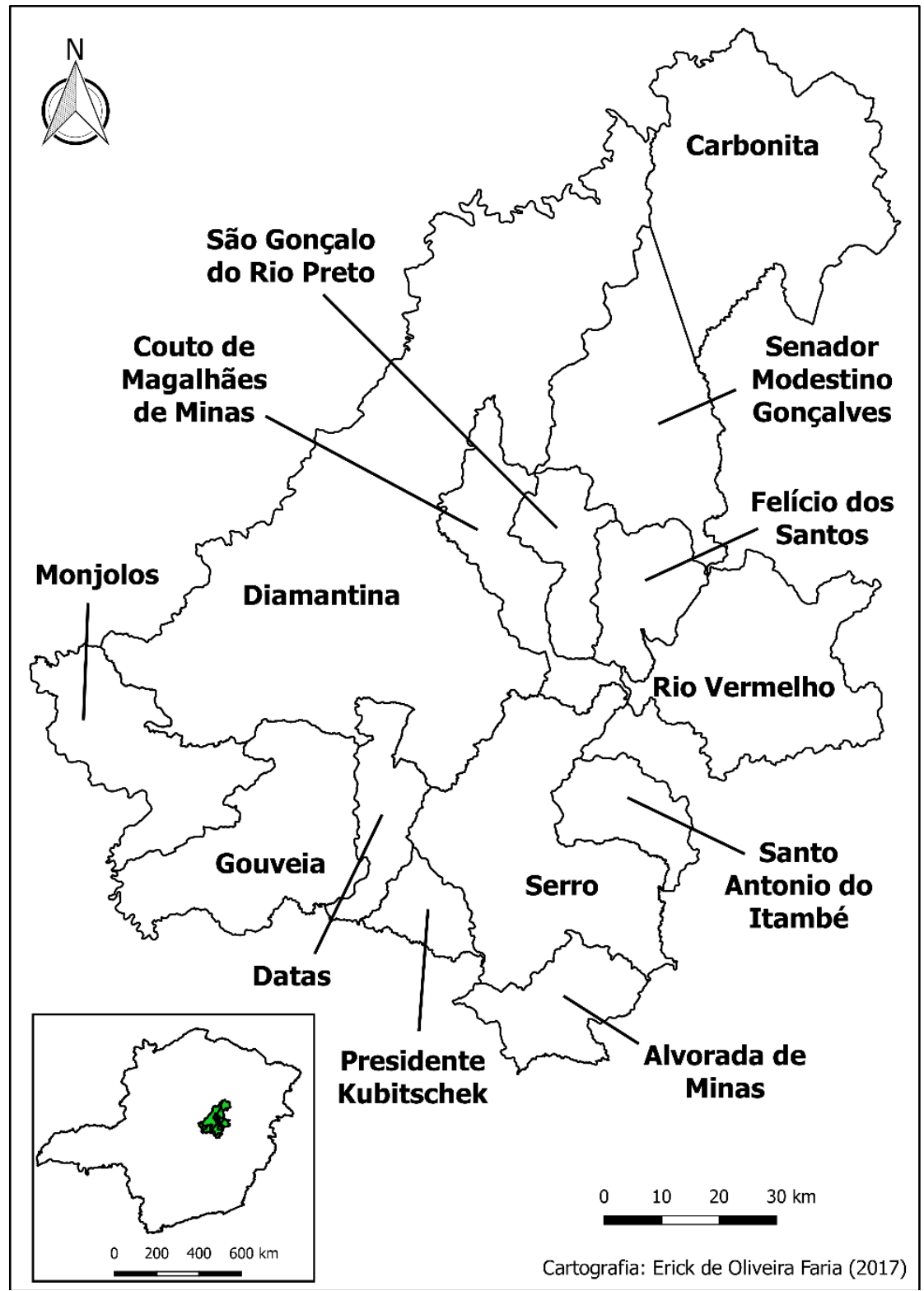

Fonte: Elaboração Própria a partir das Malhas Digitais do IBGE, 2014.

\section{METODOLOGIA}

A análise proposta neste trabalho se dá a partir de dados secundários relativos aos estabelecimentos nos setores estratégicos do turismo e seu mercado de trabalho, ainda foram coletados elementos secundários disponíveis em fontes oficiais de observatórios do Turismo da SETUR. Foram pesquisados dados relativos ao fluxo de turistas e receitas obtidas com o turismo no Estado de Minas Gerais, entre o período de 2008 e 2015, separados entre o turismo no interior do Estado e na capital Belo Horizonte. Para a análise do incentivo ao turismo no circuito dos Diamantes foi realizado um levantamento juntamente a Fundação João Pinheiro em relação ao repasse do ICMS turístico. 
Os dados relacionadas ao mercado de trabalho aqui analisadas advêm das Relações Anuais de Informações Sociais (RAIS), do Ministério do Trabalho e Emprego (MTE), assim como informações relacionadas ao fluxo de turistas e receitas geradas no turismo do Observatório do Turismo do Governo do Estado de Minas Gerais e também do Ministério do Turismo.

Para análise da economia formal por meio da RAIS, foram utilizadas as Atividades Características do Turismo (ACTs), uma relação de atividades a partir do Cadastro Nacional de Atividades Econômicas, versão 2.0 (CNAE), descritas na tabela 1. Estas ACTs foram selecionadas pelo MTur que, por sua vez, se baseou na Clasificación Internacional Uniforme de Actividades Turísticas (CIUAT) da Organização Mundial do Turismo (OMT).

\section{Tabela 1 - CNAE2.0 - Atividades Econômicas Características Do Turismo}

\section{CNAE 2.0 - ATIVIDADES ECONÔMICAS CARACTERÍSTICAS DO TURISMO}

\begin{tabular}{ll}
49124 & Transporte metroferroviário de passageiros \\
49221 & $\begin{array}{l}\text { Transporte rodoviário coletivo de passageiros, com itinerário fixo, intermunicipal, interestadual e } \\
\text { internacional }\end{array}$ \\
49299 & $\begin{array}{l}\text { Transporte rodoviário coletivo de passageiros, sob regime de fretamento, e outros transportes rodoviários não } \\
\text { especificados anteriormente }\end{array}$ \\
49507 & Trens turísticos, teleféricos e similares \\
\hline 50220 & Transporte por navegação interior de passageiros em linhas regulares \\
\hline 50912 & Transporte por navegação de travessia \\
\hline 50998 & Transportes aquaviários não especificados anteriormente \\
\hline 51111 & Transporte aéreo de passageiros regular \\
\hline 51129 & Transporte aéreo de passageiros não-regular \\
\hline 55108 & Hotéis e similares \\
\hline 55906 & Outros tipos de alojamento não especificados anteriormente \\
\hline
\end{tabular}

56112 Restaurantes e outros estabelecimentos de serviços de alimentação e bebidas

56121 Serviços ambulantes de alimentação

77110 Locação de automóveis sem condutor

77217 Aluguel de equipamentos recreativos e esportivos

79112 Agências de viagens

79121 Operadores turísticos

79902 Serviços de reservas e outros serviços de turismo não especificados anteriormente

90019 Artes cênicas, espetáculos e atividades complementares

90027 Criação artística

91023 Atividades de museus e de exploração, restauração artística e conservação de lugares e prédios históricos e atrações similares 
91031 Atividades de jardins botânicos, zoológicos, parques nacionais, reservas ecológicas e áreas de proteção ambiental

92003 Atividades de exploração de jogos de azar e apostas

93212 Atividades esportivas não especificadas anteriormente

93298 Parques de diversão e parques temáticos

93191 Atividades de recreação e lazer não especificadas anteriormente

Fonte: Organização dos autores, a partir de Organización Mundial del Turismo - OMT, 2001. 149 p.

A partir das informações de estabelecimento e vínculos da RAIS nas ACTs na região, usou-se o cálculo de Quociente Locacional (QL) para análise de concentração das atividades e vínculos das ACTs em relação ao Estado de Minas Gerais. O QL foi proposto primeiramente por Isard (1960) e tem sido amplamente utilizado em estudos econômicos que buscam analisar o desenvolvimento regional. O QL é um indicador obtido por meio da relação entre a proporção de estabelecimentos de uma atividade específica sobre o total de estabelecimentos em uma região, e a mesma proporção no Estado de Minas Gerais.

Valores de QL superiores a 1 indicam que a concentração de estabelecimentos na região é superior à do Estado de Minas Gerais, valores inferiores indicam que a concentração é inferior, e valores iguais a 1 indicam que a concentração de estabelecimentos é a mesma que a do Estado. O mesmo se aplica ao número de vínculos de uma ocupação específica.

$$
Q L=\frac{e^{1} / e^{2}}{m^{1} / m^{2}}
$$

$e^{1}=$ Número de estabelecimentos por atividade CNAE.

$e^{2}=$ Número de estabelecimentos na região de análise.

$m^{1}=$ Número de estabelecimentos por atividade CNAE no Estado de Minas Gerais.

$m^{2}=$ Número de estabelecimentos no Estado de Minas Gerais.

\subsection{Turismo em Minas Gerais}

Dados relativos às receitas geradas com o turismo em circuitos no interior do estado de Minas Gerais são escassos, sendo muitos deles desatualizados quando disponíveis, ou indisponíveis na escala municipal. Desta maneira, buscou-se apenas uma breve caracterização da atividade turística e seu impacto na economia estadual, comparando os dados de fluxo de turistas e o de receita turística no estado. Os dados utilizados são os disponibilizados pelo Observatório do Turismo em Minas Gerais.

A figura 2 mostra um crescimento do fluxo de turistas no interior de Minas Gerais, passando de 8 milhões, em 2008, para 24,4 milhões, em 2015. Na capital Belo Horizonte, o 
fluxo de turistas não foi tão crescente, apresentando, inclusive, quedas em alguns períodos, como o de 2009 ao ano de 2011.

Apesar do crescimento no fluxo no ano de 2014, ano da realização dos jogos da Copa do Mundo FIFA, o crescimento foi de apenas 800 mil turistas em Belo Horizonte, e 1 milhão no interior do Estado. Comparando com outros períodos, como por exemplo de 2011 para 2012, o crescimento do fluxo de turistas foi mais expressivo, passando de 17,3 milhões em 2011 para 21,7 milhões de turistas no interior do Estado, enquanto na capital passou de 3,5 milhões para 3,9.

Os dados de fluxo de turistas em Minas Gerais em 2014 mostram que eventos internacionais como o da Copa do Mundo FIFA não proporcionam um crescimento considerável no fluxo de turistas, comparados com 2012, quando o Estado de Minas Gerais começa a consolidar seus Circuitos Turísticos e seu planejamento no setor.

Figura 2 - Variação do Fluxo de turistas em Minas Gerais

\section{Fluxo de turistas em Minas Gerais (em milhões)}

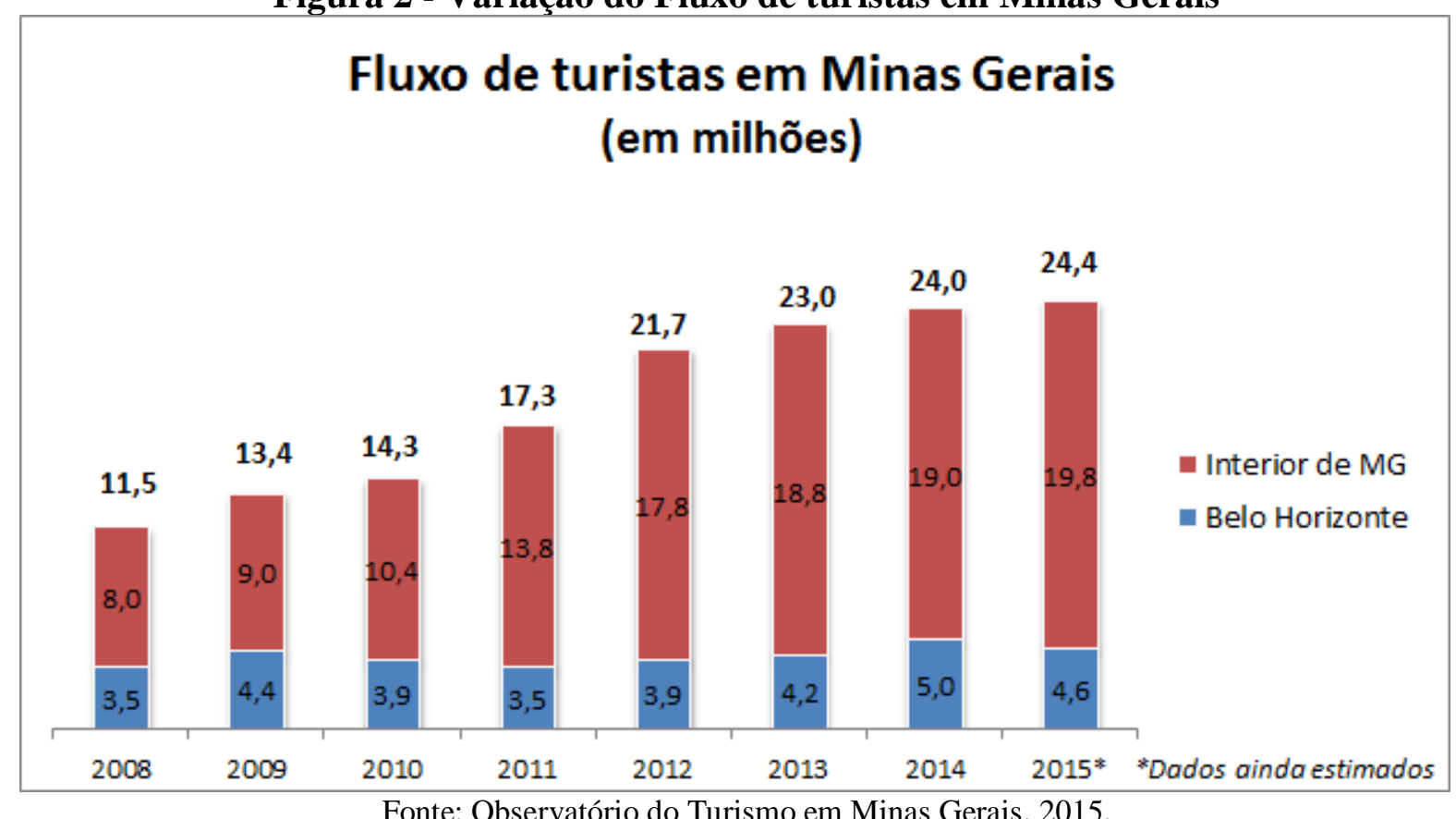

A receita turística em Minas Gerais (Figura 3) apresentou um comportamento de crescimento semelhante ao de fluxo de turistas, salvo em alguns períodos em que o crescimento das receitas foi negativo, como no período de 2011 para 2012 e de 2014 para 2015. O crescimento maior foi observado entre os anos de 2012 para 2013, com continuação no crescimento em 2014. 
Figura 3 - Variação das Receitas Turísticas em Minas Gerais Receita turística em Minas Gerais (em bilhões)

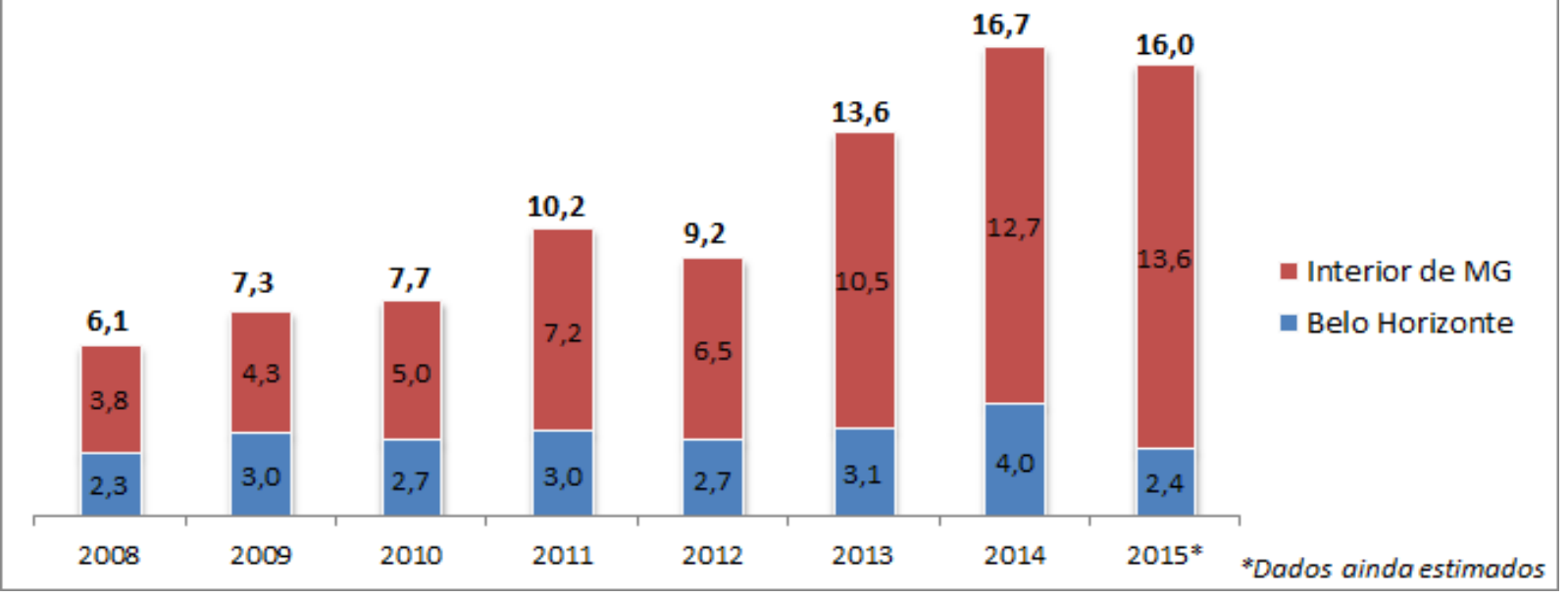

Fonte: Observatório do Turismo em Minas Gerais, 2015.

\section{INCENTIVO ECONÔMICO DO ESTADO PARA O DESENVOLVIMENTO TURÍSTICO REGIONAL}

Na compreensão de Cruz (2016), políticas públicas destinadas ao turismo podem ser compreendidas como instrumentos no desenvolvimento da realidade local. Com o intuito de incentivar o turismo nos municípios no Estado de Minas Gerais, foi criado a partir da Lei Estadual n 18.030 (2009) o ICMS Turístico, que é um valor repassado pelo Estado de Minas Gerais entre os municípios como um incentivo financeiro para trabalharem a sua gestão de turismo.

O incentivo financeiro obtido por meio da partilha do ICMS Turístico para os municípios permite que os setores das ACTs tenham um desenvolvimento econômico, e a população um ganho cultural e social. Permite também que aqueles municípios de menor porte populacional tenham em suas receitas municipais, tidas como insuficientes para o investimento em turismo, um suporte financeiro que possa potencializar seus ganhos e atrair investimentos para o setor, por meio de uma gestão turística.

Como bem ressalva Fuchs (2013), o fato de um município participar de um circuito turístico certificado, não significa necessariamente que ele possui um planejamento visando estimular o turismo, e que suas políticas públicas estejam em concordância com o plano de desenvolvimento turístico da região. 
De acordo com a Lei Estadual n. 18.030 (2009), para ter direito ao repasse, os municípios deverão anualmente seguir os seguintes critérios: ${ }^{1}$ Participar de um circuito turístico reconhecido pela Setur, nos termos do Programa de Regionalização do Turismo no Estado de Minas Gerais; Ter elaborada e em implementação uma política municipal de turismo; Possuir Conselho Municipal de Turismo (COMTUR), constituído e em regular funcionamento; Possuir Fundo Municipal de Turismo (FUMTUR), constituído e em regular funcionamento.

O critério de repasse do ICMS Turístico é definido com base no índice de investimento em turismo pelo município e o somatório dos índices de investimentos em turismo de todos os municípios habilitados a receber o incentivo, de acordo com a fórmula descrita na da Lei Estadual n. 18.030 (2009).

Dentre os 14 municípios que compõem o Circuito dos Diamantes, apenas 9 receberam algum repasse do ICMS Turístico, entre os anos de 2012 e 2015, sendo que, apenas os municípios de Datas e Felício dos Santos receberam em todos os anos (Figura 4). Analisando a Figura 4, percebe-se que o repasse de Diamantina em relação aos demais não é muito expressivo. Sendo Diamantina e Serro os municípios com maior expressão turística dentro do circuito, outros municípios de menor expressão turística como Datas, Felício dos Santos receberam valores próximos a esses, ou maiores, como é o caso de Rio Vermelho, que em 2015 recebeu quase 7 mil reais a mais do que os dois municípios de maior expressão do circuito.

\footnotetext{
${ }^{1}$ Informações retiradas no site da Secretaria de Turismo de Minas Gerais em acordo com a Lei Estadual ${ }^{\circ}$ $18.030 / 2009$.
} 


\section{Figura 4 - Valor anual de repasse do ICMS Turístico aos municípios do Circuito dos} Diamantes entre 2012 e 2013.

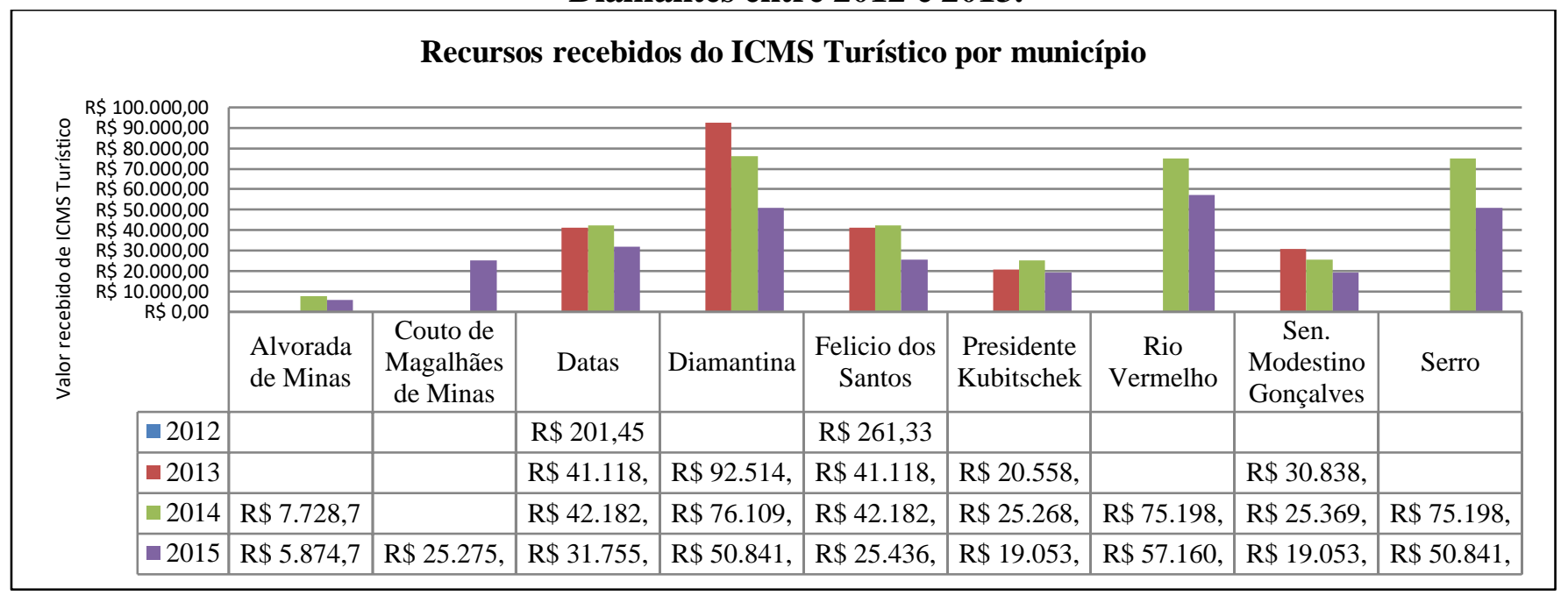

Fonte: Organização dos autores a partir dos dados da Fundação João Pinheiro, 2016.

$\mathrm{Na}$ Figura 4, percebe-se também uma queda no valor anual do repasse do incentivo financeiro aos municípios a partir do ano de 2014, fato que pode estar relacionado com a recente crise financeira do Estado de Minas Gerais, na qual houve uma queda acentuada no valor total de suas arrecadações, e entre elas o ICMS, influenciando de forma direta o cálculo referente ao ICMS Turístico.

No modelo atual, ao destinar os incentivos financeiros por município, o Estado de Minas Gerais pode estar gerando desigualdades entre seus municípios, com diferenças significativas em alguns casos. Uma alternativa a esse modelo atual seria fazer o repasse para o Circuito Turístico, e não para os municípios, onde o repasse pode ser feito de maneira igualitária. Uma análise nesse sentido, que enxerga o Circuito Turístico como uma "única região", é abordada por Tavares (2015), que propõe pensar os circuitos como clusters turísticos, e não como municípios com políticas e administrações diferentes. Tendo em comum apenas a proximidade geográfica e a participação em um circuito, tal alternativa poderia contribuir para minimizar as diferenças socioeconômicas e de atratividades turísticas entre os municípios.

Porém, mesmo com as falhas que possa ter, o ICMS turístico acaba sendo algo positivo para os municípios com menor capacidade de investimento e retenção no setor de turismo. Ao criar um critério, onde, quanto mais investir em turismo, o município recebe mais, o Estado incentiva os municípios a continuarem buscando investimentos para o setor a fim de receber o repasse. Vale ressaltar também a importância da política para o desenvolvimento de uma gestão competente para que as documentações estejam sempre de 
acordo com os critérios estabelecidos na lei para a certificação do município para receber o repasse.

\section{ATIVIDADES ECONÔMICAS DO TURISMO}

\subsection{Quociente locacional}

No intuito de compreender o arranjamento do setor turístico na economia do Circuito dos Diamantes em comparação ao total da economia formal de Minas Gerais, foi calculado o Quociente Locacional das ACTs, tanto para os estabelecimentos empregadores quanto para os vínculos formais de emprego. O estudo de concentração de estabelecimentos e vínculos formais em relação ao Estado permite enxergar quais setores da economia tem maior expressão no Circuito dos Diamantes e, assim, localizar a posição do setor turístico. E ainda, a observação de dados históricos permite verificar, mesmo que de forma descritiva, o impacto do setor na economia dos municípios componentes do Circuito dos Diamantes.

Segundo a Tabela 2, apenas 12 ACTs apresentaram algum valor positivo no ano de 2014 na RAIS para vínculos e estabelecimentos. No total, o Circuito dos Diamantes contava em dezembro de 2014 com 215 estabelecimentos e um estoque de vínculos formais, ativos em 31 de dezembro, de 838 nas ACTs.

A atividade econômica com maior número de estabelecimentos é a de Restaurantes e Outros Estabelecimentos de Serviços de Alimentação e Bebidas, com 118 estabelecimentos e, em segundo lugar, a atividade de hotéis e similares, com 47 estabelecimentos. Em contrapartida, apesar de ser a atividade com maior número de estabelecimentos no circuito, a atividade de Restaurantes e Outros Estabelecimentos de Serviços de Alimentação e Bebidas, apresenta QL's abaixo de 1, ou seja, não é uma atividade que demonstra concentração em relação ao Estado de Minas Gerais. Por outro lado, a ACT de Hotéis e Similares apresenta um QL com valor de 1,39, o que significa uma pequena concentração em relação ao Estado.

As ACTs que apresentam maior QL são as Atividades de Museus e de Exploração, Restauração Artística, Conservação de Lugares e Prédios Históricos, Atrações Similares $(5,14)$ e Atividades Esportivas não Especificadas Anteriormente $(3,19)$.

Entre as Atividades Características do Turismo que apresentaram maior valor no Quociente Locacional de vínculos formais, apenas a de Serviços Ambulantes de Alimentação não apresentou concentração também no QL de estabelecimentos, as demais atividades seguiram a dinâmica de concentração dos estabelecimentos na região em relação ao Estado. A ACT com maior QL nos vínculos foi a de Atividades de Museus e de Exploração, 
Restauração Artística e Conservação de Lugares e Prédios Históricos e Atrações Similares $(4,95)$, seguido pelas atividades de Serviços Ambulantes de Alimentação $(2,80)$, Outros Tipos de Alojamento não Especificados Anteriormente $(2,28)$ e de Hotéis e Similares $(2,08)$.

As ACTs com maior relação Vínculos/Estabelecimentos foram as de Transporte Rodoviário Coletivo de Passageiros, com Itinerário Fixo, Intermunicipal, Interestadual e Internacional $(10,6)$ e Hotéis e Similares $(5,5)$.

Tabela 2 - Número de estabelecimentos, estoque de vínculos formais de emprego ativos em 31/12 e respectivos Quocientes Locacionais (QL), e número de vínculos por estabelecimento, segundo a classe de atividade econômica - Circuito dos Diamantes, 2014. ${ }^{2}$

\begin{tabular}{|c|c|c|c|c|c|c|c|}
\hline \multirow{2}{*}{ Classe de atividade econômica (CNAE 2.0) } & \multicolumn{3}{|c|}{ Estabelecimentos } & \multicolumn{3}{|c|}{ Vínculos } & \multirow{2}{*}{$\begin{array}{l}\text { Vinc/ } \\
\text { Estab. }\end{array}$} \\
\hline & $\mathbf{N}$ & $\%$ & QL & $\mathbf{N}$ & $\%$ & QL & \\
\hline Total Economia & 215 & & & 838 & & & 3,9 \\
\hline $\begin{array}{l}\text { Transporte Rodoviário Coletivo de Passageiros, com Itinerário } \\
\text { Fixo, Intermunicipal, Interestadual e Internacional }\end{array}$ & 7 & 1,05 & 1,68 & 74 & 0,31 & 0,79 & 10,6 \\
\hline $\begin{array}{l}\text { Transporte Rodoviário Coletivo de Passageiros, Sob Regime } \\
\text { de Fretamento, e Outros Transportes Rodoviários não } \\
\text { Especificados Anteriormente }\end{array}$ & 13 & 0,97 & 1,55 & 22 & 0,27 & 0,71 & 1,7 \\
\hline Hotéis e Similares & 47 & 1,39 & 2,22 & 259 & 0,81 & 2,08 & 5,5 \\
\hline Outros Tipos de Alojamento não Especificados Anteriormente & 11 & 1,84 & 2,93 & 24 & 0,89 & 2,28 & 2,2 \\
\hline $\begin{array}{l}\text { Restaurantes e Outros Estabelecimentos de Serviços de } \\
\text { Alimentação e Bebidas }\end{array}$ & 118 & 0,49 & 0,78 & 424 & 0,34 & 0,87 & 3,6 \\
\hline Serviços Ambulantes de Alimentação & 4 & 0,93 & 1,48 & 11 & 1,09 & 2,80 & 2,8 \\
\hline Locação de Automóveis sem Condutor & 5 & 0,61 & 0,97 & 6 & 0,10 & 0,26 & 1,2 \\
\hline Agências de Viagens & 2 & 0,18 & 0,29 & 1 & 0,03 & 0,07 & 0,5 \\
\hline Artes Cênicas, Espetáculos e Atividades Complementares & 2 & 0,53 & 0,85 & 7 & 0,42 & 1,07 & 3,5 \\
\hline $\begin{array}{l}\text { Atividades de Museus e de Exploração, Restauração Artística } \\
\text { e Conservação de Lugares e Prédios Históricos e Atrações } \\
\text { Similares }\end{array}$ & 1 & 3,23 & 5,14 & 7 & 1,92 & 4,95 & 7,0 \\
\hline Atividades Esportivas não Especificadas Anteriormente & 4 & 2,00 & 3,19 & 1 & 0,09 & 0,24 & 0,3 \\
\hline $\begin{array}{l}\text { Atividades de Recreação e Lazer não Especificadas } \\
\text { Anteriormente }\end{array}$ & 1 & 0,15 & 0,24 & 2 & 0,06 & 0,16 & 2,0 \\
\hline
\end{tabular}

Fonte: Organização dos autores a partir da RAIS, TEM, 2014.

A tabela 2 nos mostra que as atividades que apresentam maior QL de estabelecimentos e vínculos, não são atividades que estão ligadas exclusivamente ao turismo, por exemplo, as

${ }^{2}$ Atividades Características do Turismo que apresentaram valor igual a zero foram omitidas na tabela. 
atividades do ramo alimentício. Os circuitos turísticos para Hall (2001), não se limitam a atender as demandas dos turistas, mas, também como resposta ao problema econômico provocado pela reestruturação na economia. Esse fato levanta uma questão pertinente se esse cenário econômico é devido ao grande número de turistas e demandas feitas por eles, ou uma demanda da própria região. A projeção do turismo para Ablas (1991) acarretará em uma série de efeitos que, complementarão as atividades econômicas locais. Considerando os aspectos sob a análise regional, o turismo proporcionará uma distribuição de renda sobre as estruturas de consumo, pelas relações de compra e venda, entre os agentes (Ablas, 1991).

\section{MERCADO DE TRABALHO FORMAL DO TURISMO NO CIRCUITO DOS}

\section{DIAMANTES}

O mercado de trabalho em turismo no Circuito dos Diamantes é um indicador importante, que permite analisar o quanto as ACTs vêm crescendo desde a criação do Circuito. Trabalhos como Mendonça et al. (2005) contemplaram esta análise acerca do mercado de trabalho formal no turismo, na cidade de Diamantina. Apesar de apresentar uma metodologia e um objeto de análise diferente, como analisar setores CNAE mais amplos do que os aqui estudados e contemplar apenas o município de Diamantina, o mesmo serve de parâmetro para compreensão da evolução do mercado de trabalho formal em turismo no circuito.

Segundo Mendonça et al. (2005), entre os períodos de 1997 e 1999 o município de Diamantina apresentou tendência de redução no saldo de vínculos formais. A partir do ano de 2000, quando o município foi elevado à categoria de Cidade Patrimônio Cultural da Humanidade pela UNESCO, o saldo de empregos voltou a ser positivo. O município apresentou entre os períodos de 2000 e 2005 um crescimento de 17\% no saldo de vínculos formais (Mendonça et al., 2005).

A tabela 3 mostra a variação do estoque de vínculos formais de ACTs no Circuito dos Diamantes de 2006, um ano após a criação do circuito, até o 2014, último período com dados disponibilizados pela RAIS. A variação do estoque de vínculos no Circuito dos Diamantes mostra que a criação do Circuito foi eficaz no que diz respeito ao crescimento da economia formal do turismo, considerando que o número de vínculos de 2006 a 2014 teve um crescimento de 95\%, quase o dobro desde a criação do Circuito (de 478 a 838, em valores absolutos). 
Entre as ACTs com maior crescimento ao longo da escala temporal em análise, destaca-se a de Restaurantes e Outros Estabelecimentos de Serviços de Alimentação e Bebidas e a de Hotéis e Similares. A primeira contava, em dezembro de 2006, com 219 vínculos e, em dezembro de 2014, demonstrou um crescimento de 93,5\%, chegando a 424 vínculos. A segunda atividade apesar de apresentar números mais modestos, teve crescimento percentual de 56,7\%, passando de 165 para 259 vínculos.

As demais atividades não demonstraram expressivo crescimento como as duas citadas anteriormente, com um estoque de vínculos que não chegou a uma centena em nenhum período aqui analisado. Percebe-se uma variação pequena que pelo comportamento inexpressivo de um ano em relação ao outro, pode-se deduzir que se trata de expectativas de fluxo e receitas com turismo.

Mesmo que os números de vínculos em algumas atividades possam parecer baixos, ressalta-se que, os mesmos tratam apenas do mercado de trabalho formal. As pessoas que trabalham em setores relacionados ao turismo, e são proprietários autônomos ou com estabelecimentos familiares, podem não haver vínculo formal registrado na RAIS. Atividades que, por exemplo, se enquadrariam no ramo alimentício como Serviços Ambulantes de Alimentação, mas não têm um vínculo formal de emprego não entram na base de dados da RAIS.

Tabela 3 - Variação do estoque de vínculos no mercado de trabalho formal das atividades econômicas do turismo em nove anos. ${ }^{3}$

\begin{tabular}{|c|c|c|c|c|c|c|c|c|c|}
\hline Classe de atividade econômica (CNAE 2.0) & 2006 & 2007 & 2008 & 2009 & 2010 & 2011 & 2012 & 2013 & 2014 \\
\hline $\begin{array}{l}\text { Transporte Rodoviário Coletivo de } \\
\text { Passageiros, com Itinerário Fixo, } \\
\text { Intermunicipal, Interestadual e Internacional }\end{array}$ & 29 & 33 & 114 & 73 & 63 & 57 & 66 & 61 & 74 \\
\hline $\begin{array}{l}\text { Transporte Rodoviário Coletivo de } \\
\text { Passageiros, Sob Regime de Fretamento, e } \\
\text { Outros Transportes Rodoviários não } \\
\text { Especificados Anteriormente }\end{array}$ & 17 & 17 & 22 & 11 & 14 & 10 & 17 & 25 & 22 \\
\hline Hotéis e Similares & 165 & 185 & 237 & 211 & 263 & 243 & 257 & 272 & 259 \\
\hline $\begin{array}{l}\text { Outros Tipos de Alojamento não Especificados } \\
\text { Anteriormente }\end{array}$ & 26 & 27 & 18 & 17 & 18 & 19 & 23 & 20 & 24 \\
\hline $\begin{array}{l}\text { Restaurantes e Outros Estabelecimentos de } \\
\text { Serviços de Alimentação e Bebidas }\end{array}$ & 219 & 223 & 229 & 246 & 305 & 302 & 366 & 397 & 424 \\
\hline Serviços Ambulantes de Alimentação & 0 & 0 & 0 & 6 & 8 & 12 & 14 & 15 & 11 \\
\hline Locação de Automóveis sem Condutor & 5 & 2 & 5 & 5 & 6 & 6 & 5 & 5 & 6 \\
\hline Agências de Viagens & 3 & 4 & 2 & 2 & 5 & 6 & 2 & 3 & 1 \\
\hline $\begin{array}{l}\text { Artes Cênicas, Espetáculos e Atividades } \\
\text { Complementares }\end{array}$ & 2 & 4 & 3 & 6 & 5 & 6 & 10 & 5 & 7 \\
\hline $\begin{array}{l}\text { Atividades de Museus e de Exploração, Restauração } \\
\text { Artística e Conservação de Lugares e Prédios }\end{array}$ & 5 & 6 & 6 & 7 & 5 & 5 & 4 & 7 & 7 \\
\hline
\end{tabular}

${ }^{3}$ Atividades Características do Turismo que apresentaram valor igual a zero foram omitidas na tabela. 


\begin{tabular}{|c|c|c|c|c|c|c|c|c|c|}
\hline $\begin{array}{l}\text { Atividades Esportivas não Especificadas } \\
\text { Anteriormente }\end{array}$ & 1 & 2 & 15 & 3 & 3 & 6 & 5 & 4 & 1 \\
\hline $\begin{array}{l}\text { Atividades de Recreação e Lazer não } \\
\text { Especificadas Anteriormente }\end{array}$ & 6 & 3 & 5 & 5 & 3 & 1 & 2 & 3 & 2 \\
\hline Total & 478 & 506 & 656 & 592 & 698 & 673 & 771 & 817 & 838 \\
\hline
\end{tabular}

Fonte: Organização dos autores a partir da RAIS, TEM, 2014.

Apesar de ser um crescimento modesto em comparação a outros Circuitos Turísticos como aponta Fuchs (2013), o Circuito dos Diamantes é uma região formada por municípios de populações modestas, que são classificados segundo o IBGE (2007) como cidades centros locais. O crescimento expressivo de algumas atividades econômicas demonstra que o modelo de Circuito que é praticado vem obtendo êxito, pelo menos em alguns pontos, partindo da análise do crescimento de vínculos formais.

\subsection{Saldo de vínculos no Circuito dos Diamantes}

Complementando a análise anterior, a Tabela 4 mostra a variação do total de admitidos, desligados e o saldo de vínculos formais entre os períodos de 2006 e 2014 no Circuito dos Diamantes. Sendo um setor da economia com uma flutuação particularmente alta no número de vínculos no setor, por causa da sua dependência do cenário econômico, o saldo de vínculos apresentou ao longo do período em análise flutuações positivas e negativas.

Com um saldo positivo de 58 vínculos ao final do ano de 2006, a tendência de crescimento não se manteve nos anos seguintes, havendo em 2007 uma queda de 20 vínculos no setor. Para o ano de 2008 em relação ao de 2009, o saldo passou de 38 vínculos positivos para 16 negativos. Uma recuperação no saldo foi observada em 2010, mas já em 2011 o saldo voltou a ser negativo. Para os anos entre 2012 e 2014, o saldo foi positivo, porém apresentando queda em 2013 e em 2014, em relação ao ano de 2012. 


\section{Tabela 4 - Variação do total de Admitidos, Desligados e Saldo de vínculos formais de emprego nas Atividades Características do Turismo, do Circuito dos Diamantes.}

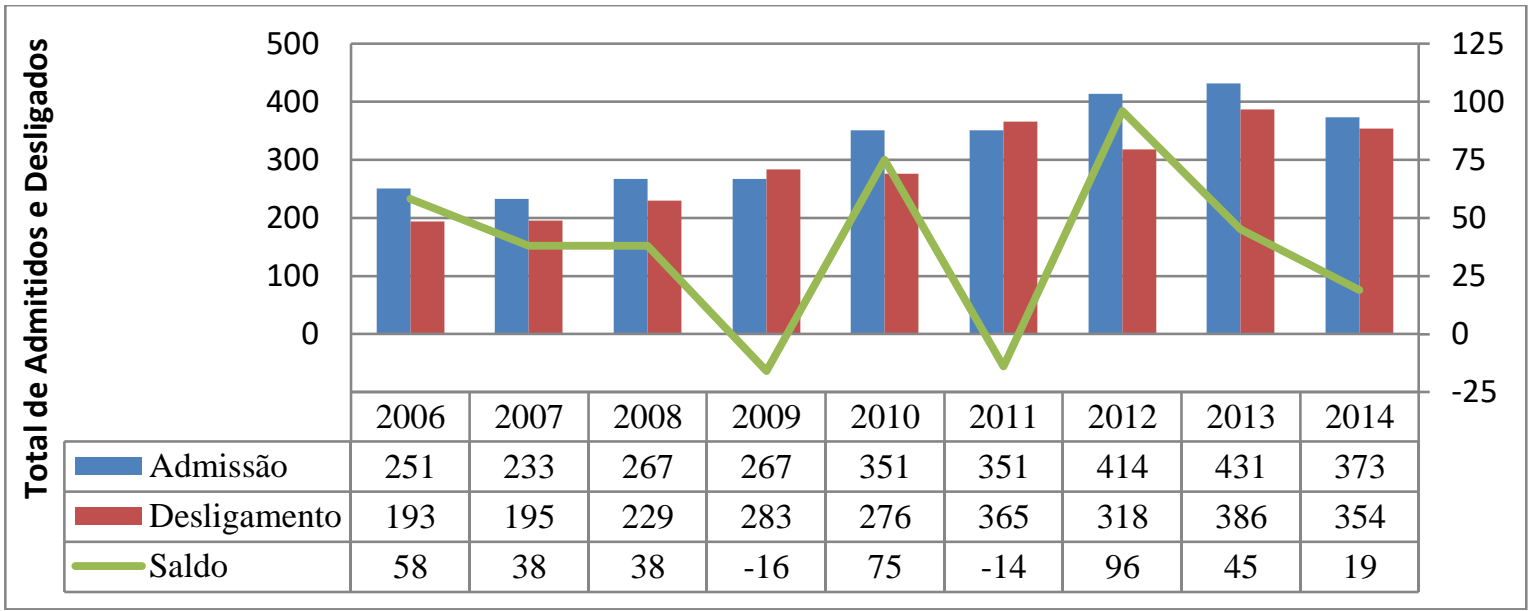

Fonte: Organização dos autores a partir da RAIS, TEM, 2014.

Uma situação peculiar nas ACTs do Circuito dos Diamantes é observada em relação ao número de admitidos e desligados por ano, em que quase todos os vínculos que são criados em um ano corresponde aos desligamentos. Nos anos em que o saldo não foi negativo, o número de desligados foi quase o mesmo do número de admitidos. Cenário esse compreensível em uma região que tem como grandes atrativos turísticos caracterizam-se como festas efêmeras, como festivais culinários, festas temáticas e a maior dentre elas, o carnaval, principalmente no município de Diamantina.

Os números de admissões e desligamentos são próximos, mas os valores são pequenos e os saldos acabam tendo um efeito positivo no final do período, somando 360 novos vínculos (como já mostrado acima, 95\% de crescimento). Esta flutuação no saldo de vínculos no Circuito dos Diamantes pode estar atrelada a uma lógica de expectativa de mercado para o ano. Sendo as ACTs serviços que dependem do fluxo de turistas na região para o crescimento, os estabelecimentos tem uma alta rotatividade de vínculos, onde, admite-se quando o fluxo de turista é grande e demite quando o fluxo cai.

Devido ao alto número de admissão e desligamentos de um ano para o outro, a tabela 3, mostra uma relativa facilidade de contratação, e estoque de mão-de-obra disponível para o setor do turismo. Esse comportamento é negativo do ponto de vista da insegurança para a mão de obra do setor com a falta de estabilidade em seus vínculos de trabalho. 


\section{CONSIDERAÇÕES FINAIS}

Os circuitos turísticos são criados com o intuito de promover o turismo regional, agrupando cidades que tem como interesse comum desenvolver atividades para a atração de turistas e investimentos no setor. Regiões com potencial turístico, localizadas próximas a parques nacionais e cidades que foram referência durante o período colonial brasileiro deixando um acervo patrimonial histórico muito grande, compartilhando uma gestão através da criação do circuito turístico buscando maior eficiência no desenvolvimento do setor.

O Circuito dos Diamantes apresentou um crescimento no que diz respeito ao número de vínculos durante o período analisado neste trabalho, nas ACTS. A grande questão é se este crescimento é devido a esta interação entre os municípios e política pública do Estado de Minas Gerais para desenvolvimento do turismo e do Circuito dos Diamantes, ou trata-se de uma demanda da própria região para este serviço. Dessa forma, atribuir o crescimento de vínculos formais à criação do Circuito dos Diamantes evidenciaria um equívoco segundo as análises deste trabalho, sendo que, as informações postas aqui são insuficientes para fundamentar tal afirmação.

Os dados de ICMS Turístico são incipientes e irregulares, o que representa uma não linearidade nos investimentos, de forma que o Estado busque a cada ano desenvolver mais o turismo no Circuito dos Diamantes. Os critérios definidos para o repasse pode ser um dos principais motivos, juntamente com outros fatores econômicos relacionados, mas, visando que o repasse é um incentivo para o desenvolvimento do Turismo nos municípios, outras maneiras mais eficazes talvez devam ser pensadas frente a este modelo atual.

No que se referem os Quocientes Locacionais, nas atividades de Restaurantes e Outros Estabelecimentos de Serviços de Alimentação e Bebidas e Hotéis e Similares, os valores são muito baixos em relação à economia do Estado de Minas Gerais. Esses valores baixos não são suficientes para sustentar uma afirmação de que estas atividades turísticas predominam na região do circuito. A única atividade que apresentou um QL considerável em relação ao Estado de Minas Gerais é a atividade de Atividades de Museus e de Exploração, Restauração Artística e Conservação de Lugares e Prédios Históricos e Atrações Similares, mas, por ser uma atividade que apresenta poucos vínculos (apenas 7 em 2014), não nos permite sustentar também que é uma atividade importante para a economia do circuito.

Outro fator de destaque na região é a alta rotatividade dos postos de trabalho, o que se traduz em insegurança para a região, não contribuindo, assim, para o tal desenvolvimento socioeconômico previsto nas políticas públicas. 


\section{REFERÊNCIAS}

Ablas, L. (1991). Efeitos do turismo no desenvolvimento regional. Turismo em Análise, 2(1), 42-52.

Árias, A. R., \& Barbosa, M. A. C. (2007). Caracterização da mão-de-obra do mercado formal de trabalho do setor turismo: estimativas baseadas nos dados da RAIS de 2004. Texto para Discussão. Rio de Janeiro: IPEA, 1308.

Brandão, H. (2001). Minas Revolucionou o Setor Turístico. In: Especial Turismo, Grandes Veredas. Jornal Estado de Minas. Belo Horizonte.

Brasil. Ministério do Trabalho e Emprego. (2017) Programa de Disseminação das Estatísticas do Trabalho. Relação Anual de Informações Sociais (RAIS). Brasília, DF. Recuperado em 20, setembro, 2017 de http://www.rais.gov.br/sitio/sobre.jsf

Cruz, E. C. (2016) A lei Robin Hood e o desenvolvimento dos municípios do Vale do Jequitinhonha. Dissertação (Mestrado em Ciências Contábeis) - Universidade Federal de Uberlândia, Uberlândia.

Emmendoerfer, M. L., Silva, F. C., \& Lima, A. A. T. F. (2011). Evidências de Inovação Social na Gestão Pública do Turismo em Minas Gerais - Brasil: O Modelo de Circuitos Turísticos em Análise. PASOS. Revista de Turismo y Patrimonio Cultural, 9(2), 397-410.

Fuchs, A. M. S. L., \& Oliveira, F. F. (2013). ICMS turístico e novas possibilidades de desenvolvimento regional para o Estado de Minas Gerais. Anais Brasileiros de Estudos Turísticos - ABET, 2(2), 54-64, Juiz de Fora, Minas Gerais.

Fundação João Pinheiro. Lei Hobin Hood: pesquisa por critério ICMS Turístico. Recuperado em 20 setembro, 2016 de http://www.fjp.mg.gov.br/robin-hood/index.php/leirobinhood

Hall, C. M. (2001). Planejamento Turístico: políticas, processos e relacionamentos. São Paulo: Contexto.

Instituto Brasileiro de Geografia e Estatística - IBGE. (2007). Regiões de influência das cidades. Rio de Janeiro: IBGE.

Isard, W. (1960). Methods of regional analisys. Cambridge, Massachusets: The MIT Press.

Lei $n^{o}$. 13.341, de 28 de outubro de 1999 (1999). Dispõe sobre a criação da Secretaria de Estado do Turismo de Minas Gerais. Belo Horizonte, 1999.

Lei $n^{o}$. 18.030, de 12 de janeiro de 2009 (2009). Dispõe sobre a distribuição da parcela da receita do produto da Arrecadação do ICMS pertencente aos municípios de Minas Gerais. Belo Horizonte, 2009.

Mendonça, M. P., Bernardes, P, Silva, M. O., \& Costa, N. G. B. (2005). Evolução do mercado de trabalho no turismo em Diamantina: uma contribuição para reflexões de estratégias voltadas para o desenvolvimento local. Belo Horizonte: PUC Minas. 
Observatório do Turismo de Minas Gerais. Recuperado em 20, setembro, 2017 de https://www.observatorioturismo.mg.gov.br/

Organización Mundial del Turismo - OMT (2001). Cuenta satélite de turismo: recomendaciones sobre el marco conceptual. Nueva York: Naciones Unidas; Madrid, 149.

Secretaria de Estado do Turismo de Minas Gerais - SETUR/MG. (2003). O que é um Circuito Turístico?. Belo Horizonte, MG. Recuperado em 20, setembro, 2017 de http://www.turismo.mg.gov.br/circuitos-turisticos/informacoes-administrativas

Solha, K. T. (2005). Órgãos Estaduais de Turismo no Brasil. In: Trigo, L. G. G.; Netto, A. P.; Carvalho, M. A.; Pires, P. S. (Org.). Análises Regionais e Globais do Turismo Brasileiro. São Paulo: Roca, 1, 39-47.

Tavares, J. (2015). Cluster de Turismo e as Experiências do Estado de Minas Gerais na Formação de Circuitos Turísticos. Revista Turismo em Análise, 26(3), 558-587.

Veloso, M. P. (2003). Turismo: simples e eficiente. São Paulo: Roca, 199 p.

FORMATO PARA CITAÇÃO DESTE ARTIGO

FARIA, E. O., \& TEIXEIRA, M. B. B. (2018). Economia formal e desenvolvimento econômico turístico do Circuito dos Diamantes - MG. Revista de Turismo Contemporâneo, 6(2), 211-231. 